\title{
Fatigue Investigation of the Interface Shear Performance in Asphalt Pavement
}

\author{
Cristina Tozzo ${ }^{1}$, Antonio D'Andrea ${ }^{1}$, Domingo Cozzani ${ }^{1} \&$ Andrea Meo $^{1}$ \\ ${ }^{1}$ Sapienza University of Rome, Via Eudossiana 18, Roma, Italy \\ Correspondence: Cristina Tozzo, DICEA, Sapienza University of Rome, Via Eudossiana 18, 0018 Roma, Italy. \\ E-mail: cristina.tozzo@uniromal.it
}

Received: September 10, 2013

Accepted: January 22, $2014 \quad$ Online Published: February 17, 2014

doi:10.5539/mas.v8n2p1

URL: http://dx.doi.org/10.5539/mas.v8n2p1

\begin{abstract}
This paper shows the interlayer fatigue performance evaluated by the Sapienza shear testing machine. The tests can be performed by placing double layer specimens in several inclinations, in order to reproduce a variety of expected ratios between the normal and the shear stress. The machine manages loads with any kind of waveform and is particularly able to simulate the stress trends expected in field in points located just outside the wheel path In this experimentation, the machine applies a triangular waveform load computed by a linear elastic multilayer program at the depth of the first pavement interface. A fatigue law is estimated considering the number of repetitions that causes the interface failure. A linear regression in the log-log graph suitably fits the experimental results for the analyzed conditions of temperature and interface type.
\end{abstract}

Keywords: pavement durability, interface shear behavior, interlayer bonding fatigue, shear test

\section{Introduction}

The performance of the road structure is directly influenced by the bond conditions between pavement layers. The impacts of bond failures are more evident where the vehicles turn, brake, go uphill or downhill, accelerate or decelerate. Slippage cracking and permanent deformations are the most typical effects. The subsequent modification of the stress distribution affects the service life with a significant reduction (Khweir \& Fordyce, 2003).

Furthermore, the common assumptions of a completely full bond or full slip between the layers are both incorrect. In fact, the interaction between the layers is not that strong to prevent a relative displacement. Even when the failure occurs, a fully sliding is not possible because friction has to be taken in consideration.

The damage caused by bond failures is so important that the design methods of bituminous pavements should be improved considering an interface fatigue performance criterion, besides the bottom-up and top-down tensile fatigue, rutting and low temperature cracking. That will improve the accuracy of the predictions about pavement lifetime.

The settlement process of this new criterion is at its first step. One of the biggest difficulties is the large variety of stress conditions that the vehicles' wheels generate in the different points of the interface in the real pavements. Concerning this subject, a parametric study of the stress conditions at different depths was presented by Xiaoyang et al. (2013). The test machines proposed so far are able to reproduce just few of those stress conditions.

The most common type of testing modality is the direct shear test, where a shear load is applied at the interface with the possibility to add also a normal force. The output of the test is a parameter named shear strength. It is computed as the peak level of the unit shear resistance, opposed by the interface when one layer is pushed across the other, until the failure. Several testing devices have been developed worldwide with different working schemes. They are able to test cylindrical or prismatic specimens with different sizes (Sangiorgi et al., 2002; Raab \& Partl, 2004; Ferrotti et al., 2012) and have been used to evaluate and compare the influence on the interface shear strength of several factors such as the tack coat efficiency (Mohammad et al., 2002), the surface conditions (Mohammad, 2012) or the surface profile (D’Andrea et al., 2013; Loprencipe \& Cantisani, 2013).

Generally, these testing machines work in monotonic modalities thanks to the application of an established displacement rate. Such a scheme has become the most popular within the researchers because of their installing 
and setting simplicity. However, the prolonged application of high stress is not close to the interface loading condition in the field. In fact, the vehicles apply on the pavement repetitive short loadings. Furthermore, just in certain points those loadings are oriented in the same direction for all the time of the wheel passage; in other points they assume opposite orientations during the loading cycle. Finally, very various loading conditions can be experienced in different positions at the interface. That can happen also in the same point in different moments, depending on the lateral wander of traffic, which should be studied by statistical analysis methods (Cantisani \& Loprencipe, 2013; Mauro \& Brando, 2013).

The aim of the present research is to reproduce some of the stress trends which actually happen at the interface during the wheel passage. Therefore the device used in this research is able to repetitively apply dynamic loading cycles, in order to obtain information about the interface shear fatigue performance.

\section{Bibliography}

In the recent years, the interface shear behavior has been one of the most investigated research fields because of the growing understanding of the interlayer bond importance in the pavement performance decay. Due to the absence of a standard in the testing mode, several shear devices have been developed, but only few have been designed to work in dynamic mode, because the installation and set are characterized by great complexity with respect to the monotonic devices. Furthermore, the dynamic tests need long time to perform when the loading levels are low, as happens in several locations into the pavement structure.

A comparison between the results of monotonic and dynamic tests was conducted by Crispino et al. (1997); they developed a dynamic shear test and assessed that the dynamic shear reaction modulus is three times higher than the monotonic one.

Carr et al. (2001) developed a direct shear box able to test slabs (320 by $200 \mathrm{~mm}$ ) under repeated shear loads combined with the application of a normal load. Kruntcheva et al. (2001) showed that the disadvantage of this equipment is the non-uniform interface stress distribution that needs proper assumptions to interpret the results.

Romanoschi and Metcalf (2001) designed a shear fatigue device where the longitudinal axis of the specimen forms an angle of $25.5^{\circ}$ with the vertical in order to have the shear stress proportional to the normal one and equal to half of its value. The loading conditions used to test the specimens consider a haversine load, applied vertically by the loading machine, and assumes as comparative parameter of the interface fatigue properties the number of cycles that leads to an increase of $1 \mathrm{~mm}$ in the permanent deformation.

Also, in the "Mechanics and modeling of materials and structures in civil engineering" Laboratory of the University of Limoges, France, a modified compact shear test device was developed to study the shear fatigue behavior of different asphalt mixtures and tack coat materials. The machine was used on prismatic specimens $(70 \times 30 \times 100 \mathrm{~mm})$, formed by three parts, obtained by gluing back to back two samples of the same couple of layers. With such a working scheme the shear load can be applied on the unrestricted middle layer of the double specimen in monotonic or repeated mode until failure. Because of the low rigidity of the test frame, a new device named new double-shear testing frame was developed by Diakhaté et al. (2011) in order to test specimens at high frequency and low temperature. In this case, the gluing of the specimen on the steel plates that apply the shear load ensures the best alignment of the steel plates in relation to the double loading configuration and a perfect fit of the specimen in the device. The experimental program was intended to carry out both fatigue and "oligocyclic" tests under alternate sinusoidal force control, in order to span a number of loading cycles between 10 and several millions.

Among the shear tests devices are also included the two machines designed and developed by D'Andrea and Tozzo $(2012,2013)$ at the Sapienza University of Rome, both able to work in monotonic conditions under a loading machine that applies a set displacement rate. In the devices, named SHST and SIST Machine, the shear and the normal load act together on the specimen during the test, so to have a composite state of stress. In the SHSTM the normal load is constant during the test while in the SISTM the two components proportionally vary. These two machines were recently transformed to perform dynamic tests under the loading appliance used for fatigue tests (D’Andrea \& Fiore, 2003).

\section{Objective}

The aim of this paper is to present the results of shear fatigue tests carried out with the dynamic shear test device called SIST Machine. The device can be located under a dynamic loading machine. In this way, the shear fatigue behavior of the interface can be analyzed considering loading conditions similar to some of the real ones as occurs for the vehicles transit. For the particular working scheme of the device, the load is divided in dynamic normal stress and shear stress at the interface. 
The study will start with the analysis of the stress levels expected for the pavement structure when a moving wheel load transits on the surface; these will be calculated with CIRCLY, a software for the mechanistic analysis and design of road pavements. The trend through time of the stress at the first interface between binder and wearing course will be inferred from a simply static analysis, by considering its output as an influence curve for a fixed point. That curve will be imposed as waveform for the force applied by the loading machine on the device.

Tests will be performed by reproducing the amplitude of the two stress components as evaluated by CIRCLY for heavy axles. These test conditions are to try to simulate realistically the fatigue damage rise at the interface. Moreover, tests with higher stresses combinations will be performed (oligocyclic fatigue test), in order to contribute to a better definition of the fatigue line on the plane Stress vs. Number of Repetitions. A fatigue law will be proposed, according to the experimental results.

\section{Experimental Program}

\subsection{Specimens Preparation}

The double layer specimens have been constructed to reproduce the first interface of a pavement, with binder and wearing course. The two layers were manufactured with different contents of the same 60/70 bitumen and different granulometric size distributions. For the binder course a mix of calcareous aggregates $(20 \mathrm{~mm}$ maximum size) and a bitumen content of $4,5 \%$ have been selected, while for the wearing course the mixture has been composed of basalt and calcareous aggregates ( $10 \mathrm{~mm}$ maximum size) with a bitumen content of 5,5\%. Cylindrical moulds $130 \mathrm{~mm}$ high, with an interior diameter of $100 \mathrm{~mm}$, have been used for the specimen manufacturing under the Marshall Compactor. The blows have been applied only on the upper surface of each layer as many times as the bulk density complied the most common acceptance requirements for the Italian public work contracts: minimum $98 \%$ of the bulk density of the same mixture compacted in standard Marshall mode (EN 12697). That purpose demanded 125 blows for the binder and 150 blows for the wearing course.

The lower layer, about $60 \mathrm{~mm}$ high, was left to cool at room temperature after the compaction. The interface was treated to improve the adhesion with the application of a tack coat. The application rate selected for this study has been $0.4 \mathrm{~kg} / \mathrm{m}^{2}$ of residual bitumen, according to the Italian common prescription. Prior to perform the shear test, all specimens were left to cool for more than 24 hours.

\subsection{Apparatus}

The Sapienza Inclined Shear Test Machine (SISTM), a prototype designed and developed at the Sapienza University in the recent years, has been judged useful as test device for the evaluation of fatigue performance.

This is a direct shear machine similar to the device used by Romanoschi (Romanoschi \& Metcalf, 2001); two half moulds (100 mm interior diameter) hold the cylindrical double-sample and ensure the location of the specimen under the loading machine in several inclinations. The SISTM brings the innovation of a joint, which engages the top half of the equipment at the loading machine and avoids that this upper part of the device could weight the specimen.

The gap between the two half moulds is fixed at $1 \mathrm{~cm}$ with the interface $5 \mathrm{~mm}$ apart. The device is equipped with LVDT for the displacements measurements. A ball bearing plate allows the sliding of one part against the other. For the cyclic working modality, a special attachment for the dynamic loading machine has been manufactured as shown in Figure 1.

The relationships between the vertical load (F) applied by the loading machine and the load components transmitted on the interface are the following:

$$
T=F \cdot \sin \alpha \quad \text { and } N=F \cdot \cos \alpha
$$

where $\mathrm{N}$ is the normal load, $\mathrm{T}$ is the shear load and $\alpha$ is the angle between the longitudinal axis of the specimen and the vertical.

Once set the specimen angle, the ratio between the shear and normal stress is established and cannot be changed during the test. In this study, the angle has been fixed at $60^{\circ}$; then the shear stress is $\sqrt{ } 3$ times the normal one. 

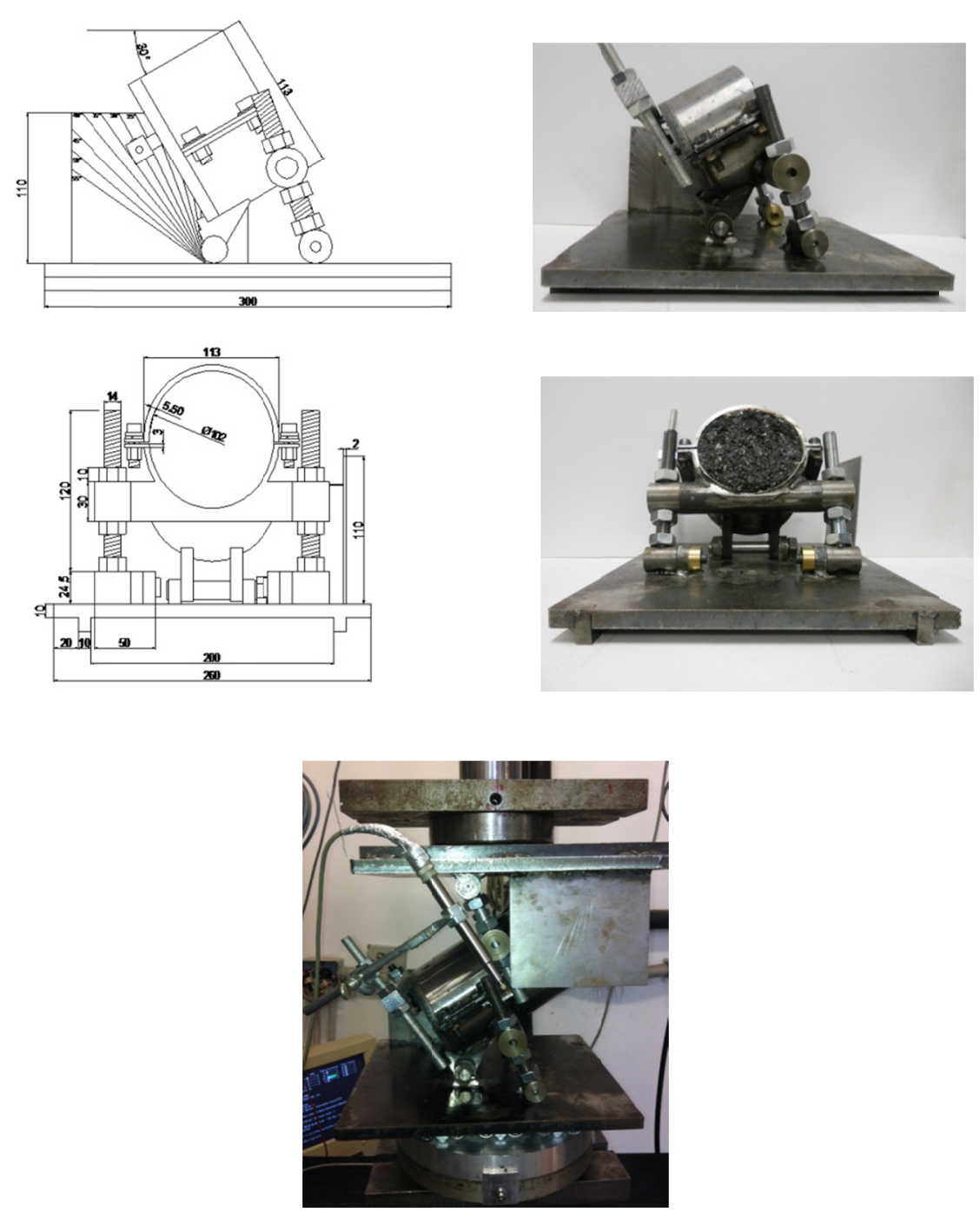

Figure 1. SISTM device

\subsection{Loading Conditions}

In order to establish the level of $\mathrm{F}$ which has to be applied, it is important to estimate the level of stress commonly acted within real pavement structures when a wheel load passes along the surface using a numerical modelling as practice in pavement design (Bonin et al., 2007; Villani et al., 2010). For this purpose, the software CIRCLY was selected. The input data shown in Table 1 were considered for the simulation of three typical road pavements: a semi-rigid and two flexible pavements, one light and one heavy, when a single wheel or a dual wheel axle is moving. 
Table 1. Input data for the CIRCLY simulation

\begin{tabular}{|c|c|c|c|c|}
\hline \multirow[t]{7}{*}{ CASE 1) } & Layer & Thickness [mm] & $\mathrm{E}[\mathrm{MPa}]$ & $\mathrm{N}$ \\
\hline & Wearing course & 40 & 7000 & 0.35 \\
\hline & Binder & 60 & 6000 & 0.35 \\
\hline & Base & 120 & 5000 & 0.35 \\
\hline & Cement Stabilized & 130 & 2000 & 0.2 \\
\hline & Sub-base & 175 & 150 & 0.40 \\
\hline & Subgrade & - & 50 & 0.40 \\
\hline \multirow[t]{6}{*}{ CASE 2) } & Layer & Thickness [mm] & $\mathrm{E}[\mathrm{MPa}]$ & $\mathrm{N}$ \\
\hline & Wearing course & 40 & 7000 & 0.35 \\
\hline & Binder & 60 & 6000 & 0.35 \\
\hline & Base & 200 & 5000 & 0.35 \\
\hline & Sub-base & 225 & 150 & 0.40 \\
\hline & Subgrade & - & 50 & 0.40 \\
\hline \multirow[t]{7}{*}{ CASE 3) } & Layer & Thickness [mm] & $\mathrm{E}[\mathrm{MPa}]$ & $\mathrm{N}$ \\
\hline & Wearing course & 30 & 7000 & 0.35 \\
\hline & Binder & 40 & 6000 & 0.35 \\
\hline & Base & 120 & 5000 & 0.35 \\
\hline & Sub-base & 130 & 150 & 0.40 \\
\hline & Subgrade & - & 50 & 0.40 \\
\hline & & LOAD & & \\
\hline \multicolumn{2}{|c|}{ single wheel axle $120 \mathrm{kN}$} & & \multicolumn{2}{|c|}{ dual wheel axle $120 \mathrm{kN}$} \\
\hline radius of contact area & $158 \mathrm{~mm}$ & & us of conta & $115 \mathrm{~mm}$ \\
\hline
\end{tabular}

The layers were considered fully bond. The normal and the tangential stress along the driving direction were evaluated on the different alignments drawn in Figure 2.

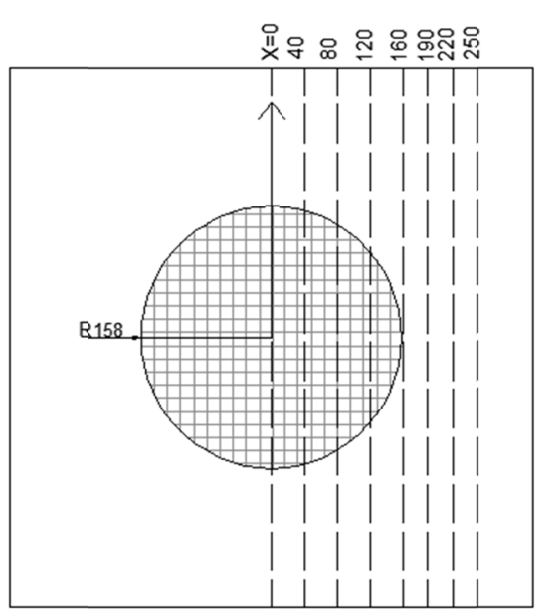

a)

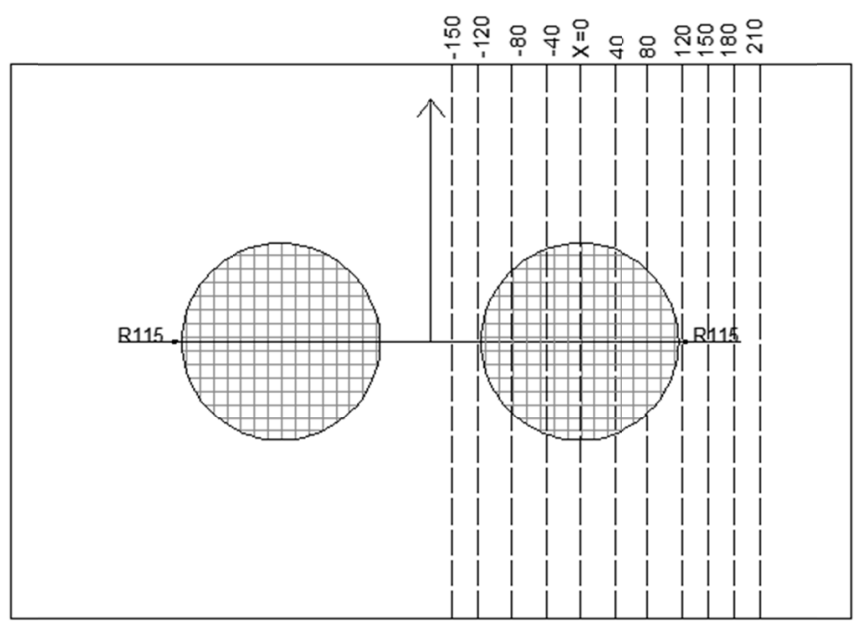

b)

Figure 2. Alignments for output extraction (single and dual wheel) 
Some results are shown in Figure 3, for the single wheel at the alignments of $x=0, x=80, x=160, x=190$. The $\sigma_{z z}$ and the $\tau_{\mathrm{xz}}$ are plotted, identifying the $\mathrm{x}$ axis as the perpendicular direction to the vehicles motion. Very similar results were obtained for dual wheel at similar distance from the external wheel print edge, when the inflating pressure is the same as the single wheel. The graphs of Figure 3 can be viewed not only as static stress distributions in the space, but also as stress trends in the time, in order to define the influence curves. For the purpose of this research, the stress trends were derived at the depth of the first interface for a vehicle speed of 15 $\mathrm{km} / \mathrm{h}$.
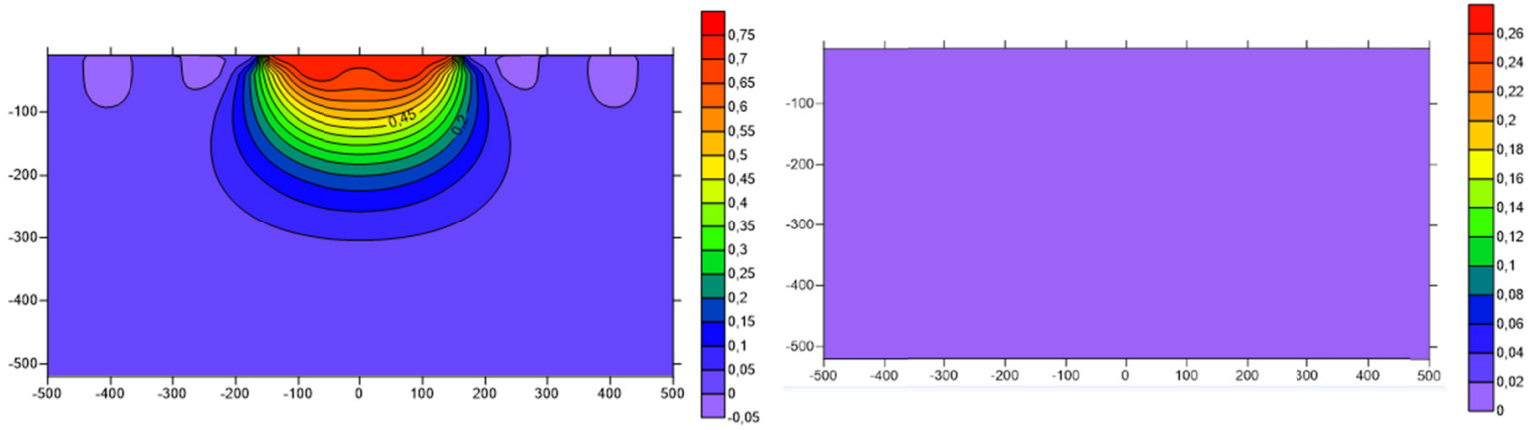

a)
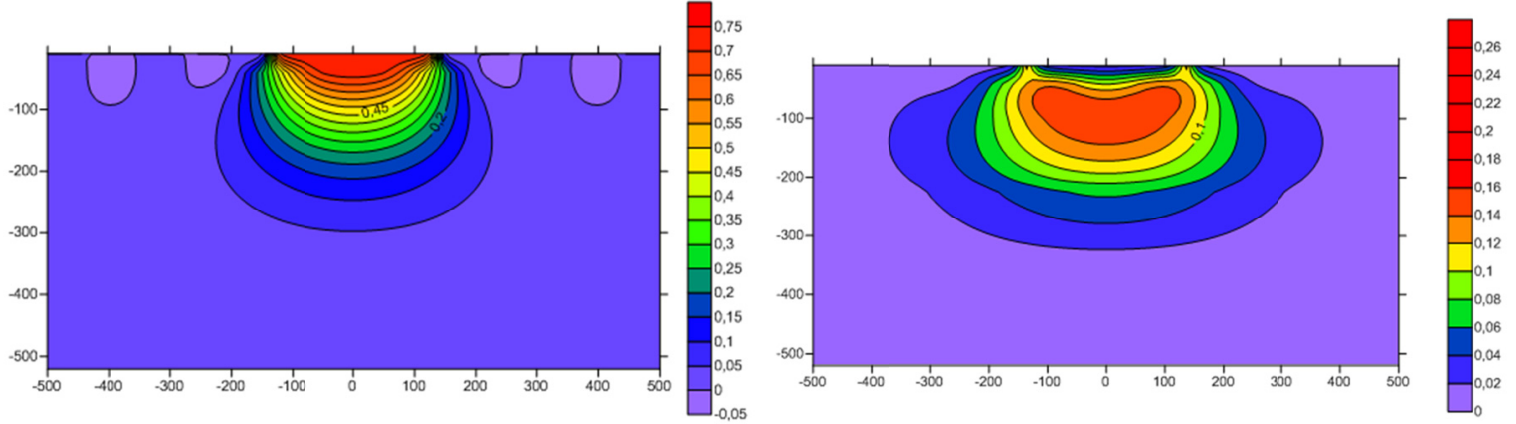

b)
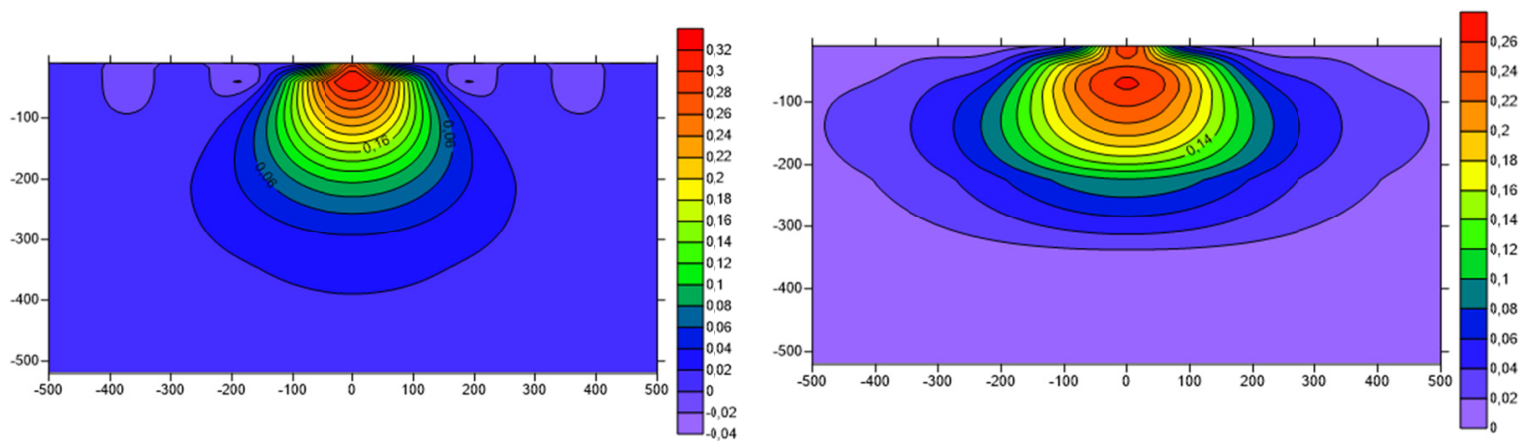

c)
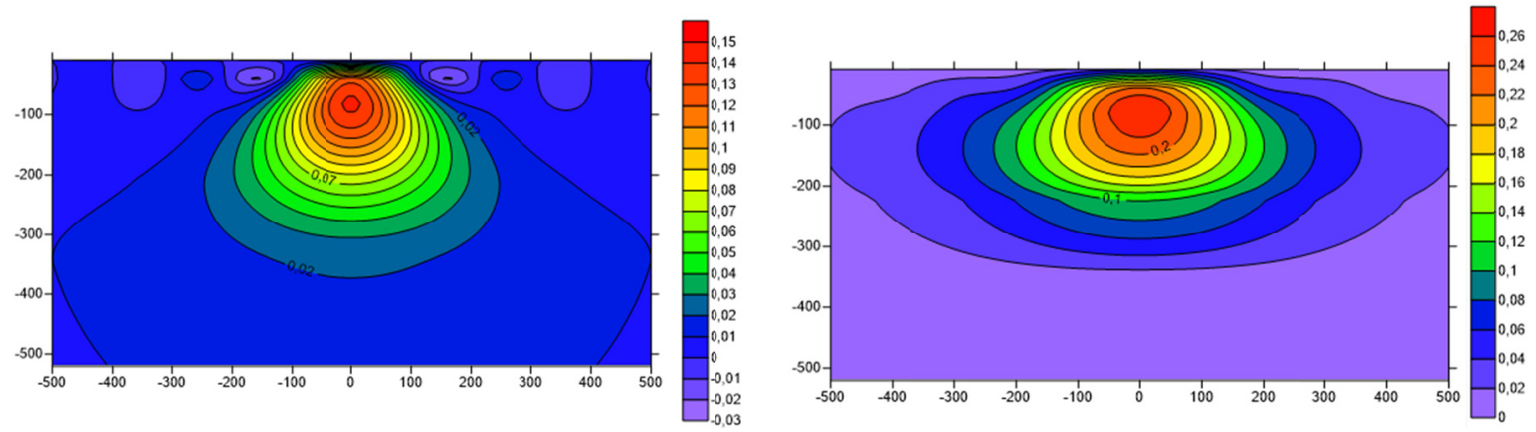

d)

Figure 3. Semirigid pavement - normal (left side) and shear (right side) stress due to a single wheel along vertical plane on the alignments at 0 (a); 80 (b); 160 (c); 190 (d) $\mathrm{mm}$ 
In Figure 4, the trends through time of the normal and shear stress are reported for some of the investigated positions. At the central position $(\mathrm{x}=0)$, or in the other positions under the wheel print (i.e. $\mathrm{x}=80$ ), the two trends are very different. On the contrary, out of the vertical projection of the wheel print there is a clear proportionality between shear and normal stress. In fact, for the alignments between 170 and $200 \mathrm{~mm}$ from the center of the loading single wheel area, the levels of $\sigma$ and $\tau$ are approximately proportional each other. The proportionality rate is roughly constant for the whole period of loading.

The SIST Machine is able to reproduce these conditions. The diagrams in Figure 4 show that for the alignment at $190 \mathrm{~mm}$ the ratio $\tau / \sigma$ is equal to that you can obtain by setting the longitudinal axis of the specimen at $60^{\circ}$ with the vertical.

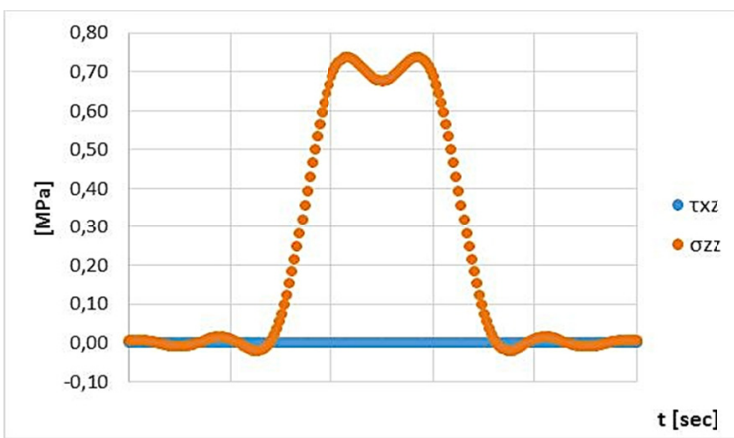

a)

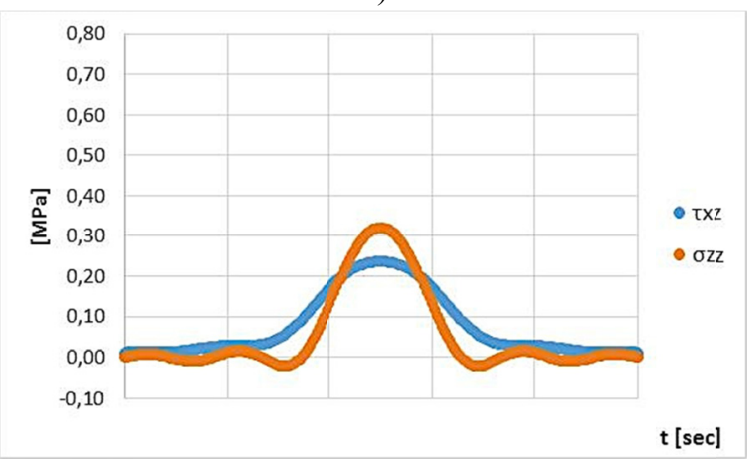

c)

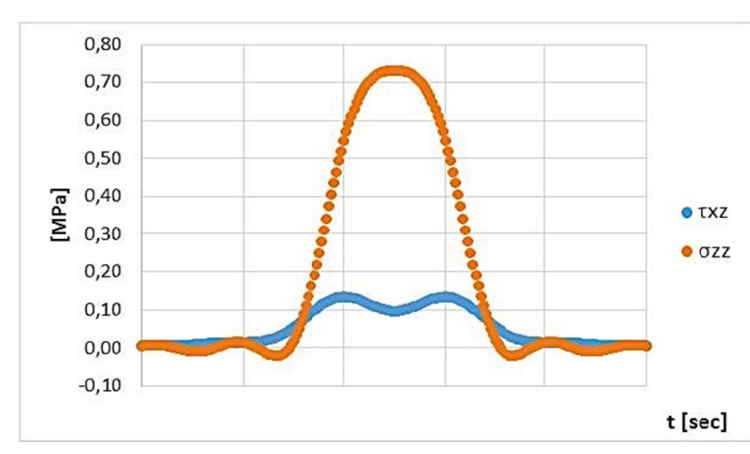

b)

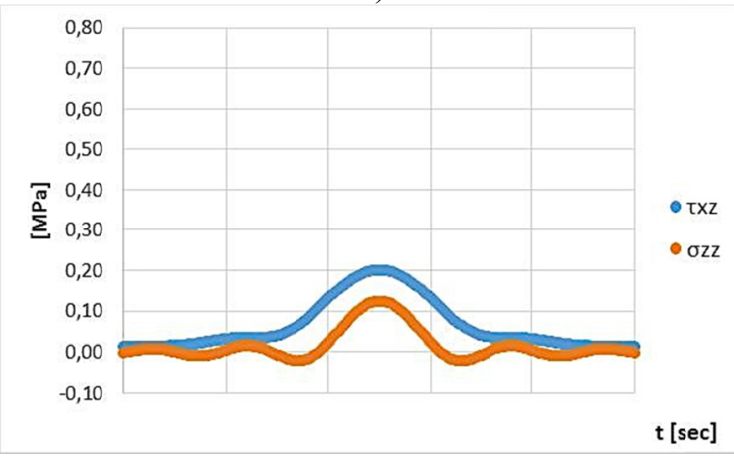

d)

Figure 4. Stress trends at the first interface for a semi-rigid pavement at the alignments of 0 (a), 80 (b), 160 (c) and 190 (d) $\mathrm{mm}$ from the center of the loading single wheel area

The stress trends are very similar in the semirigid and the strong flexible pavements. For the light flexible pavement, where the wearing course is thinner and the global pavement stiffness is lower, a ratio $\tau / \sigma$ similar to that given by setting the inclination at $60^{\circ}$ is reached at $180 \mathrm{~mm}$ from the center and the stress peak is higher, as shown in Figure 5.

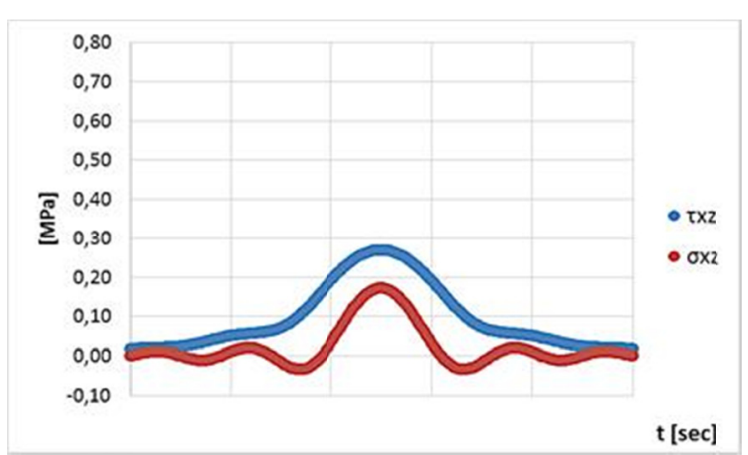

a)

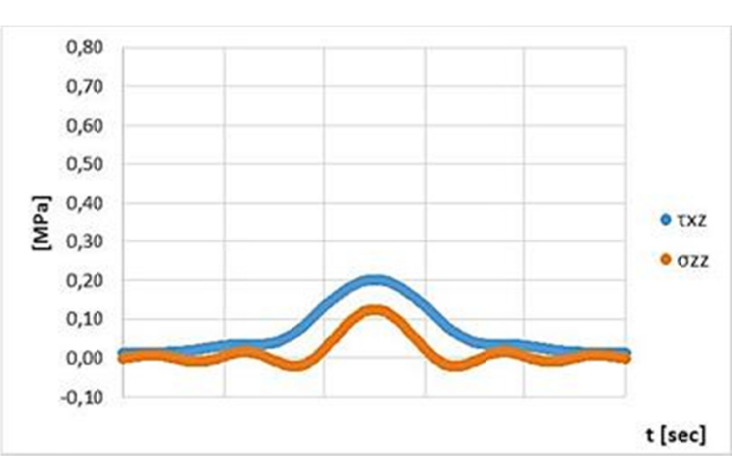

b)

Figure 5. Stress trends at the first interface for a light flexible (a) and semi-rigid (b) pavement, respectively, at the alignments of 180 and $190 \mathrm{~mm}$ from the center of the loading single wheel area 
Consequently, a triangular waveform has been applied by the loading machine during the tests. It reproduces the trends that the pavement structure records for the normal and shear stress at the first interface just outside the loading area. The triangular impulse has been repeated always in the same way for all time of the fatigue test long. That corresponds to the hypothesis of a null trajectory scattering of the vehicles, as is the case of a strict channeled bus lane.

The fatigue behavior has been analyzed for different loading amplitudes. Changing the amplitude, the loading time has been kept unmodified.

\subsection{Tests' Plan}

A summary for the loading conditions of the experimental program is shown in Table 2, referring to the peak of the normal stress $\sigma_{z z}$ applied in every cycle. The lower stress levels (first two rows of the Table 2) are around the values estimated by CIRCLY for heavy axles. The investigation of lighter load states, representative of less weighted axles, could be very useful to have a complete experimental support for fatigue law, but the testing time would become very long. Then they are missing in the present research. Vice versa, tests at high stress level are not time consuming (oligocyclic tests) and rapidly supply useful information to confirm the fatigue trend and possibly to early estimate the behavior of different tack alternatives (last rows of the Table 2).

The test temperature has been kept at $20 \pm 0.5^{\circ} \mathrm{C}$ for all the experimentation, by a room control and monitoring system. The standard cycle provides that the rest time equals the loading time. The total cycle duration is $0.2 \mathrm{~s}$. At the stress level given by CIRCLY this duration is enough to complete the recovery of the elastoviscous effects. On the other hand, at higher stresses the relaxation needs more time for the recovery. In those cases the planned load cycle provides longer relaxation times ( 0.4 and $0.9 \mathrm{~s})$. As consequence, the total cycle duration becomes respectively 0.5 and $1 \mathrm{~s}$.

Table 2. Experimental loading conditions

\begin{tabular}{ccccc}
\hline$\sigma_{\mathrm{zz}}$ peak $(\mathrm{MPa})$ & $\tau_{\mathrm{xz}}$ peak $(\mathrm{MPa})$ & $\mathrm{F}(\mathrm{kN})$ & loading time $(\mathrm{s})$ & relaxation time $(\mathrm{s})$ \\
\hline 0.08 & 0.14 & 1.31 & 0.1 & 0.1 \\
0.16 & 0.28 & 2.62 & 0.1 & 0.1 \\
0.24 & 0.42 & 3.94 & 0.1 & 0.4 \\
0.40 & 0.69 & 6.56 & 0.1 & 0.9 \\
0.80 & 1.39 & 13.12 & 0.1 & 0.9 \\
\hline
\end{tabular}

For all the five conditions, a preload of $0.3 \mathrm{kN}$ has to be applied for the loading machine set up requirements; this preload can be neglected thanks to its low value in relation to the applied force (F). A typical response curve of the test is shown in Figure 6.

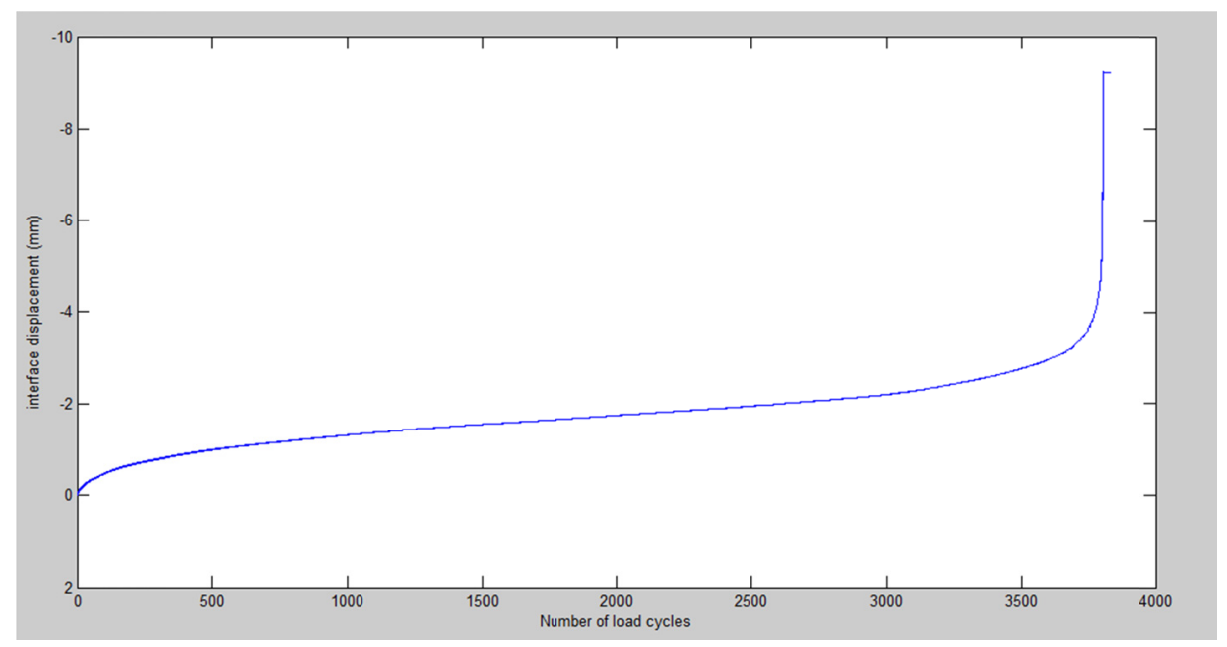

Figure 6. Typical response curve of the interface displacement VS Number of load cycles 
Looking at the evolution of the interface displacement with the number of load applications, the failure is conventionally fixed at the point where the response curve records the maximum curvature before the displacement indefinite increasing $\left(\mathrm{N}_{\text {fatigue }}\right)$.

\section{Results}

The double layer specimens have been tested with a multiplicity of 5 for all the investigated load conditions. The fatigue results are shown in Figure 7.

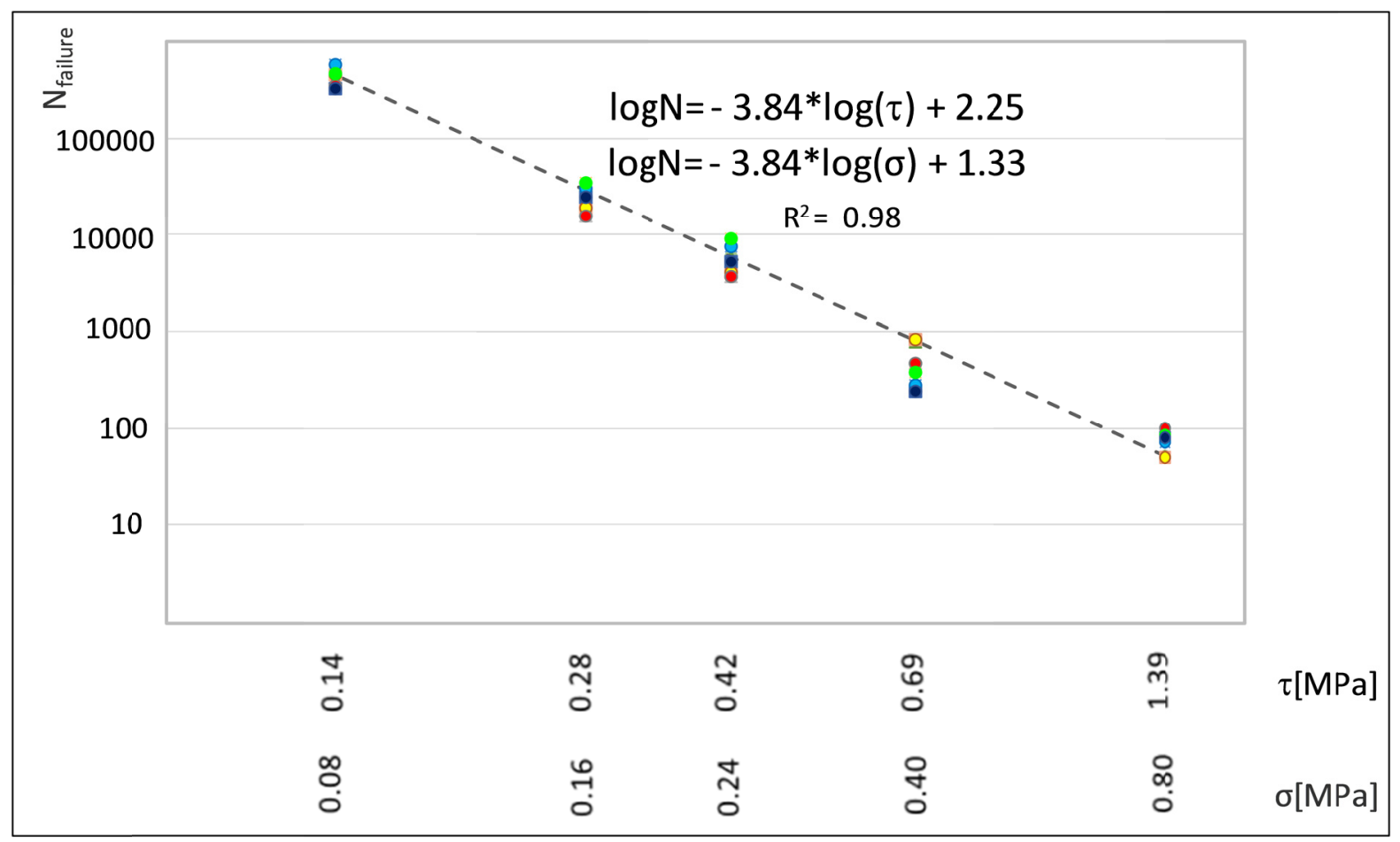

Figure 7. Results at $20^{\circ} \mathrm{C}$ with a test angle of $60^{\circ}$

With the increasing of the applied cyclical load level, the number of repetitions that the interface can support decreases consistently. For the maximum stress (oligocyclic tests), the specimen bears a number of fatigue repetitions of a few tens. For load amplitude similar to those experienced in the reality when braking o turning stresses are absent, the number of supported load applications increases significantly.

The average $\mathrm{N}_{\text {fatigue }}$ outcomes for the analyzed stress values are suitably fitted with a linear regression. What it is to notice the high $\mathrm{R}^{2}$ value gained for the presented tests. Varying the inclination of the device, the evolution of shear fatigue damage in points located at different distances from that edge can be analyzed.

The fatigue law shown in Figure 7 is valid just for $20^{\circ} \mathrm{C}$ and with the studied materials and interface conditions, but it incites to some remarks. At a distance from the wheel print edge where the ratio $\tau / \sigma$ is similar to that fixed in the test machine with an angle of $60^{\circ}(\mathrm{x}=190 \mathrm{~mm})$, the CIRCLY simulation shows that the peak of the normal stress on the interface is about $0.12 \mathrm{MPa}$ for a tire inflating pressure of $0.8 \mathrm{MPa}$. This stress is reduced by half for half inflating pressure. The regression line is characterized by an exponential trend with approximately an exponent of 4 (see Figure 7). If the regression line can be considered valid also for stress levels lower than those tested in lab, like $0.06 \mathrm{MPa}$, then it will be possible to compare the damage potential of these two different passages. In fact, at the alignment of $190 \mathrm{~mm}$, about $30 \mathrm{~mm}$ from the wheel print edge, one passage of a wheel inflated at e.g. $0.8 \mathrm{MPa}$ generates a stress of $0.12 \mathrm{MPa}$ and $\mathrm{N}_{\text {failure }}$ about 90000 , while a wheel inflated at e.g. 0.4 MPa generates a stress of $0.06 \mathrm{MPa}$ and $\mathrm{N}_{\text {failure }}$ about 1400000 . That means that one passage of a wheel inflated at $0.8 \mathrm{MPa}$ causes the same shear damage as about 16 passages of a wheel inflated at $0.4 \mathrm{MPa}$.

\section{Conclusions}

The Sapienza Inclined Shear Test Machine (SISTM), a prototype designed and developed at the Sapienza University in the recent years, has been modified to be used in the evaluation of fatigue performance of double 
layer cylindrical specimens. Several inclinations can be easily set, in order to reproduce a large variety of combinations between the normal and the shear stress.

The device is able to reproduce some of the stress combinations which occur during the wheel passage. In particular it reproduces the conditions of points situated at the interface, next to the edge of the wheel path. In those positions the shear stress is headed always in the same direction for the whole duration of the vehicle passage. Also in the lab load cycle the shear stress is always applied in the same direction.

Setting the longitudinal axis of the specimen at $60^{\circ}$ with the vertical corresponds to choose a position at about 30 $\mathrm{mm}$ from the edge of the wheel. Under this condition, the fatigue behavior has been analyzed and a fatigue law has been achieved.

Even if the SIST Machine is able to reproduce some significant states of stress, they are just a few of those experienced by the pavements, because that type of device obliges to set and maintain a fixed proportionality between the normal and shear applied load. A more complete analysis of the interface stress conditions requires the combination of different tests' results performed with several machines, which are able to reproduce other normal and shear stress ratios, as the pavement structure simulation indicates.

\section{References}

Bonin, G., Cantisani, G., Loprencipe, G., \& Ranzo, A. (2007). Dynamic effects in concrete airport pavement joints. Industria Italiana del Cemento, 77(834), 590-607.

Cantisani, G., \& Loprencipe, G. (2013). A Statistics Based Approach for Defining Reference Trajectories on Road Sections. Modern Applied Science, 7(9), 32-46. http://dx.doi.org/10.5539/mas.v7n9p32

Carr, A. G. (2001). The behavior of layered pavement structures: the dynamic shear box. Project Report, The University of Nottingham, Nottingham, UK.

Crispino, M., Festa, B., Giannattasio, P., \& Nicolosi, V. (1997). Evaluation of the interaction between the asphalt concrete layers by a new dynamic test. Presented at the Eighth International Conference on Asphalt Pavements.

D'Andrea, A., \& Fiore, N. (2003) Fatigue life of asphalt concrete with rubber grains. In A. Varvani-Farahani, C.A. Brebbia. Fatigue Damage of Materials - Experiment and analysis. Advances in Damage Mechanics (pp. 65-74). ISBN: 1-85312-979-8. WITpress, June 2003 (united kingdom).

D’Andrea, A., \& Tozzo, C. (2012). Interlayer Shear Failure Evolution with Different Test Equipments. Procedia - Social and Behavioral Sciences, 53, 556-567. http://dx.doi.org/10.1016/j.sbspro.2012.09.906

D’Andrea, A., Russo, S., \& Tozzo, C. (2013). Interlayer shear testing under combined state of stress. Advanced Materials Research, 723, 381-388. http://dx.doi.org/10.4028/www.scientific.net/AMR.723.381

D'Andrea, A., Tozzo, C., Boschetto A., \& Bottini, L., (2013). Interface Roughness Parameters and Shear Strength. Modern Applied Science, 7(10), 1-10. http://dx.doi.org/10.5539/mas.v7n10p1

Diakhaté, M., Millien, A., Petit, C., Phelipot-Mardelé, A., \& Pouteau, B. (2011). Experimental investigation of tack coat fatigue performance: Towards an improved lifetime assessment of pavement structure interfaces. Construction and Building Materials, 25, 1123-113, http://dx.doi.org/10.1016/j.conbuildmat.2010.06.064

Ferrotti, G., Canestrari, F., Pasquini, E., \& Virgili, A. (2012). Experimental evaluation of the influence of surface coating on fiberglass geogrid performance in asphalt pavements. Geotextiles and Geomembranes, 34, 11-18. http://dx.doi.org/10.1016/j.geotexmem.2012.02.011

Khweir, K., \& Fordyce, D. (2003). Influence of layer bonding on the prediction of pavement life. ICE J.Trans. 156(TR2), 73-83. http://dx.doi.org/10.1680/tran.2003.156.2.73

Kruntcheva, M. R., Collop, A. C., \& Thom, N. H. (2001). Shear box test: finite element modelling. Project Report PGR01-05, NCPE, Nottingham, UK.

Loprencipe, G., \& Cantisani, G. (2013). Unified Analysis of Road Pavement Profiles for Evaluation of Surface Characteristics. Modern Applied Science, 7(8), 1-14. http://dx.doi.org/10.5539/mas.v7n8p1

Mauro, R., \& Brando, F. (2013). Update on the Statistical Analysis of Traffic Counting on Two-Lane Rural Highways. Modern Applied Science, 7(6), 67-80. http://dx.doi.org/10.5539/mas.v7n6p67

Mohammad, L. N., Raqib, M. A., \& Huang, B. (2002). Influence of asphalt tack coat materials on interface shear strength. Transportation Research Record: Journal of the Transportation Research Board, 1789(1), 56-65. http://dx.doi.org/10.3141/1789-06 
Mohammad, L. N. (2012). Optimization of Tack Coat for HMA Placement (Vol. 712). Transportation Research Board. Project 09-40 ISSN 0077-5614 ISBN 978-0-309-21397-4. Library of Congress Control Number 2012934201.

Raab, C., \& Partl, M. N. (2004). Interlayer shear performance: experience with different pavement structures. Proceedings of the 3rd Eurasphalt \& Eurobitume Congress, May 2004, vol. 1, pp. 535-545. Vienna.

Romanoschi, S., \& Metcalf, J., (2001). Characterization of Asphalt Concrete Layer Interfaces. Transportation Research Records Journal Transportation Research Board, 1778, 132-139. http://dx.doi.org/10.3141/1778-16

Sangiorgi, C., Collop, A. C., \& Thom, N. H. (2002). Laboratory assessment of bond condition using the Leutner shear test. Proceedings of the 3rd International Conference Bituminous Mixtures and Pavements, Thessaloniki.

Villani, M. M., Liu, X., Scarpas, A., \& D'Andrea, A. (2010). Numerical modeling of the mechanical response of recycled materials in embankments. Numerical Methods in Geotechnical Engineering-Proceedings of the 7th European Conference on Numerical Methods in Geotechnical Engineering (pp. 569-574).

Xiaoyang, J., Baoshan, H., \& Lihan, L. (2013). A simplified approach for evaluating interlayer shear resistance in asphalt pavement. Presented at the Transportation Research Board 92nd Annual Meeting.

\section{Copyrights}

Copyright for this article is retained by the author(s), with first publication rights granted to the journal.

This is an open-access article distributed under the terms and conditions of the Creative Commons Attribution license (http://creativecommons.org/licenses/by/3.0/). 